\title{
Alternative moisture sensitivity test
}

\author{
Adam Zofka ${ }^{\mathrm{a}}$, Maciej Maliszewski ${ }^{\mathrm{a}}$, Alexander Bernier ${ }^{\mathrm{b}}$ \\ ${ }^{a}$ Road and Bridge Research Institute, Instytutowa 1, Warsaw 03-302, Poland \\ ${ }^{b}$ Stantec Consulting, $50 \mathrm{~W} 23 \mathrm{rd}$ St. New York, NY 10010, USA
}

\begin{abstract}
This study examines recently proposed test method called the Moisture Induced Stress Tester (MiST). The primary objective of this test method is to identify stripping potential in asphalt materials. In the course of presented study, the MiST testing was performed on the hotmix asphalt (HMA) field samples from six Long-Term Pavement Performance (LTPP) test sections in the US as well as on the field- and laboratory-compacted warm-mix asphalt (WMA) samples produced in a drum plant. Wearing surface cores from the LTPP test sections were evaluated in the MiST, and water samples before and after the test were analyzed using Infrared (IR) spectrometry. The warm-mix specimens were MiST conditioned and compared to the traditional Tensile Strength Ratio tests (AASHTO T283) as well as their bulk specific gravities were measured before and after the treatment. The results showed comparable results between MiST conditioning and the T283 for the HMA samples but similar comparison was not valid for the tested WMA specimens. Furthermore, the IR analysis identified significant peaks related to the asphalt presence at various concentrations in the water after testing, however additional data is needed in order to formulate more general conclusions from the observed trends.
\end{abstract}

Keywords: moisture damage; moisture susceptibility; tensile strength ratio.

\begin{tabular}{|ll}
\hline Nomenclature & \\
AASHTO & American Association of State Highway and Transportation Officials \\
ATR FT-IR & Attenuated Total-Reflectance Fourier Transform Infrared spectrometer \\
Gmb & Bulk specific gravity \\
HMA & Hot-Mix Asphalt \\
ITS & Indirect Tensile Strength \\
LTPP & Long-Term Pavement Performance program \\
MiST & Moisture Induced Stress Tester \\
RAP & Recycled Asphalt Pavement \\
TSR & Tensile Strength Ratio \\
WMA & Warm-Mix Asphalt
\end{tabular}

\section{Introduction}

Moisture sensitivity of asphalt pavements is a complex phenomenon caused by many different factors. From aggregatebinder incompatibilities to bad plant and paving practices, there is abundant opportunity to place moisture-susceptible pavement [1]. New technologies such as Warm-Mix Asphalt (WMA) and Low-Energy Asphalt (LEA) further increase the potential for moisture in aggregate during production with lower required temperatures. As states continue to implement these new technologies, the need for a rapid and sensitive method for detecting moisture susceptibility is required. Current practices for many State Highway Agencies, (SHA) including the Connecticut Department of Transportation (ConnDOT), require over 32 hours of conditioning for accelerated moisture susceptibility identification. The concept of pore pressure applied by water at elevated temperatures was integrated into an alternative accelerated moisture conditioning system known as the Moisture Induced Stress Tester (MiST). Alternative technologies such as the MiST can greatly improve the efficiency and precision for quality assurance by providing faster and more reliable results.

Corresponding author: Adam Zofka. E-mail address: azofka@ibdim.edu.pl

http://dx.doi.org/10.3846/enviro.2014.181

(C) 2014 The Authors. Published by VGTU Press. This is an open-access article distributed under the terms of the Creative Commons Attribution License, which permits unrestricted use, distribution, and reproduction in any medium, provided the original author and source are credited. 
Moisture at the aggregate-binder interface is common cause for stripping [1]. Many tests from Hamburg-Wheel Tracking to the Texas Boiling Test utilize high-moisture as an environment for accelerate testing of moisture susceptibility. There are several common types of stripping failures in pavement and they are summarized in [1]. Detachment is the separation of asphalt from the aggregate surface by loss of adhesion. Displacement is the separation of aggregate and binder by a previous break in the binder film. Spontaneous emulsification is a process in which the water particles become suspended in asphalt. Two physical stripping phenomena are pore pressure and hydraulic scouring. While all these failures are grouped under the common term, "stripping", the test procedures summarized below often can only detect one or several phenomena, and cannot identify all stripping susceptibilities.

Previous work conducted by [2] provided insight to the chemical processes in asphalt stripping phenomena. Their research performed several solvent baths after varying levels of aging to determine which functional groups within asphalt binder had the strongest adsorption to several different aggregates. It was found that in general, ketones had the strongest adsorption to aggregate, while anhydrides demonstrated the weakest bond. Further work has continued in this vein of research [3] and with more modern measuring devices [4] quantified the soluble components of asphalt binder after first dissolving the binder in toluene. Based on this work, the researchers identified aldehydes, alcohols and phenols as watersoluble components of the binder [4].

The first model of the MiST was constructed in 2002. A study performed at Mississippi Transportation Research Center (2005) emphasized the benefits and disadvantages of this preliminary design. Initially, the MiST monitored turbidity of the water over time, as well as slow cycle times [5]. The MiST version 9, used in this study no longer evaluates turbidity, but can condition more specimens at once than the initial models and cycles pore pressure at a significantly faster rate. The MiST 1 cycled loads at 5.55 cycles $/ \mathrm{min}$ whereas the MiST 9 runs a much improved $18.5 \mathrm{cycles} / \mathrm{min}$.

Early work with the MiST compared several HMA treatments and determined the MiST did not correlate with AASHTO T283 results [5]. Further research has since been conducted and found a better correlation [6][8]. It should be mentioned that there are other testing devices which combine elevated temperatures and pressure to accelerate moisture damage in the laboratory conditions [9].

\section{Study objectives}

The objective of this study was to evaluate the Moisture Induced Stress Tester (MiST) as a means of accelerated moisture susceptibility testing for asphalt materials. Using Long-Term Pavement Performance (LTPP) cores from 6 test Specific Pavement Studies (SPS-9A) in Connecticut as well as laboratory compacted and field cores from two WMA and a control HMA projects in Connecticut, the following tests were undertaken:

- Fourier Transform Infrared Spectroscopy (FT-IR)

- Bulk Specific Gravity (AASHTO T166 and ASTM D6752 - 09)

- Indirect Tensile Strength Testing (AASHTO T283)

It was hypothesized that similar TSR values would be measured using a modified Lottman procedure (AASHTO T283) and the MiST conditioning procedure. Additionally, it was speculated that as stripping occurs, FT-IR would be able to quantify different levels of leached asphalt in the water sampled from the MiST device.

\section{Moisture Induced Stress Tester}

The MiST machine uses a cyclic pore pressure loading and high water temperatures to simulate a harsh moisture condition for asphalt pavement. Previous studies were performed to determine the optimal temperature and cycles for a wide range of material [5][8]. In this study it was decided to use the recommended test conditions based on the outcome of these studies in order to determine whether or not custom test procedures would be required for adaptation of the MiST for Connecticut conditions. The recommended test conditions are $60{ }^{\circ} \mathrm{C}$ water bath, and 3.500 cycles achieving $276 \mathrm{kPa}$. The specimen is sealed in the chamber saturated in water, and the test initiates once the temperature reaches a minimum threshold value of $50^{\circ} \mathrm{C}$. The machine schematic is presented in Fig. 1. 


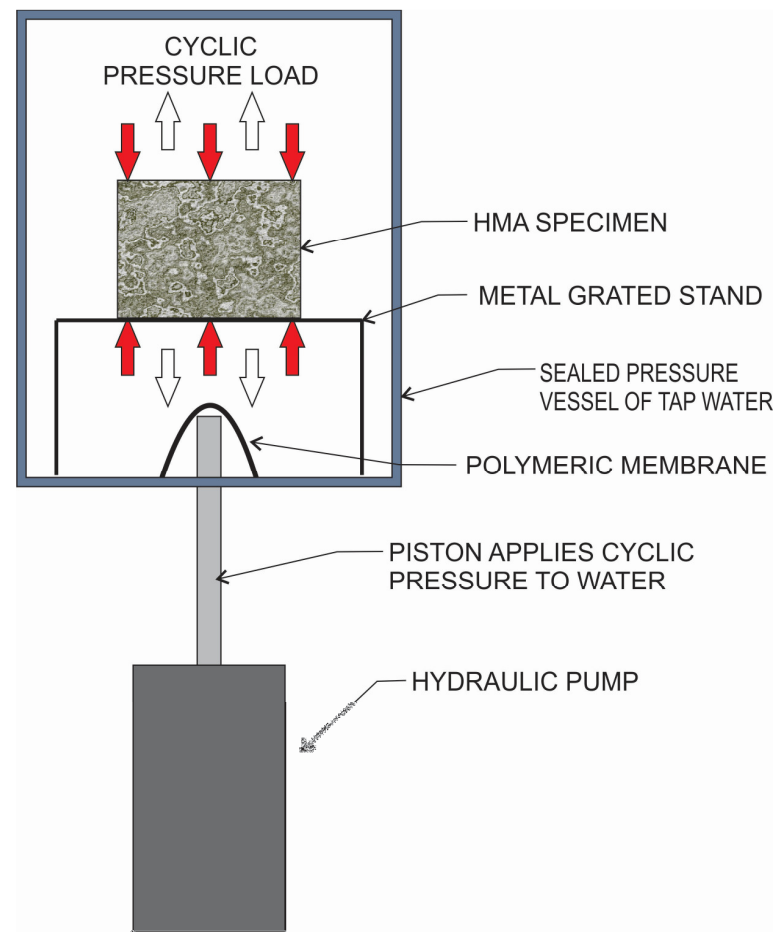

Fig. 1. Moisture Induced Stress Tester by Instrotek

\section{Experimental plan}

In total 54 field samples and laboratory specimens were evaluated using three different treatments. From the field, nine cores from the WMA test sections and control as well as eighteen samples from the LTPP test sections were MiST conditioned. The remaining laboratory compacted specimens were either controls, MiST conditioned or conditioned according to AASHTO T283 as described in the subsequent paragraph. The differences between each treatment were quantified using a combination of bulk specific gravity as well as the indirect tensile strength test.

The six LTPP sections which are evaluated in this study were part of the SPS-9A experiment sponsored by the Federal Highway Administration. These particular sections were placed in Connecticut in 1997 and the differences between the sections are outlined in Table 1. It should be noted that the first 3 sections contain 20\% of Recycled Asphalt Pavement (RAP) whereas the other 3 sections did not contain any RAP in their mix design.

While several of the sections exhibited polishing of the wearing surface aggregate over the 12 years in-service, section 090961 and 090962 demonstrated severe stripping problems, as shown by the core displayed in Fig. 2.

The WMA test sections were placed on Rt. 70 in Connecticut in July, 2010. The three 1-km sections were paved as a $50 \mathrm{~mm}$ overlay on a two-lane collector road in both traffic directions. One section was a conventional HMA while the two WMA trial sections contained (a) Sasobit wax additive, (b) water injection for foaming asphalt. Mix was sampled for the lab compaction at the plant and field cores were taken during the construction. The site was a 20 minute haul distance from the plant.

Three gyratory compacted specimens from each WMA treatment and the HMA control group were compacted in a Superpave gyratory compactor to a height of $95 \mathrm{~mm}$. After a curing period, the specimens were conditioned to a temperature of $25^{\circ} \mathrm{C}$ for 2 hours and tested in the indirect tensile strength test. A second set of 3 cores from each treatment was saturated in a vacuum pump for 7 minutes after which the specimens were placed in a freezer at $-18{ }^{\circ} \mathrm{C}$ for 16 hours. After the freezing cycle, the cores were conditioned at $60{ }^{\circ} \mathrm{C}$ for 24 hours. Finally, these cores were submerged in a $25{ }^{\circ} \mathrm{C}$ water bath for 2 hours. After the conditioning period the indirect tensile strength test is performed at $50 \mathrm{~mm} / \mathrm{min}$ [10]. This is the standard procedure for AASHTO T283.

Table 1. Summary of LTPP SPS 9-A sections placed in Colchester, CT

\begin{tabular}{lllllll}
\hline Section ID & 090901 & 090902 & 090903 & 090960 & 090961 & 090962 \\
\hline Direction & EB & EB & EB & WB & WB & WB \\
\hline ConnDOT Log Mileage & $\begin{array}{l}25.48- \\
27.48\end{array}$ & $27.48-29.70$ & $29.70-31.72$ & $31.72-29.64$ & $29.64-27.56$ & $27.56-25.48$ \\
\hline Top layer thickness, in & 2.5 & 2.5 & 2.5 & 2.5 & 2.5 & 2.5 \\
\hline Mix Type & Class 1 & Superpave & $\begin{array}{l}\text { Superpave } \\
\text { Alternative }\end{array}$ & Class 1 & Superpave & Superpave \\
& & & & & Alternative & \\
\hline
\end{tabular}


A. Zofka et al. / The $9^{\text {th }}$ Conference Environmental Engineering. Selected Papers, Article number: enviro.2014.181

\begin{tabular}{|c|c|c|c|c|c|c|}
\hline Virgin Binder Grade & AC-20 & PG 64-28 & PG 64-22 & AC-10 & PG 58-34 & PG 58-28 \\
\hline Percent Binder & 5.4 & 5.3 & 5.3 & 5.0 & 4.8 & 5 \\
\hline AV & 4.4 & 3.6 & 3.3 & 2.8 & 4.8 & 4.8 \\
\hline VMA & 16.8 & 14.4 & 13.7 & 13.9 & 14.9 & 15.5 \\
\hline RAP content & 0 & 0 & 0 & $20 \%$ & $20 \%$ & $20 \%$ \\
\hline $\begin{array}{l}\text { Anti-strip agent content by } \\
\text { weight of binder }\end{array}$ & 0 & $0.25 \%$ & $0.25 \%$ & 0 & $0.375 \%$ & $0.375 \%$ \\
\hline
\end{tabular}

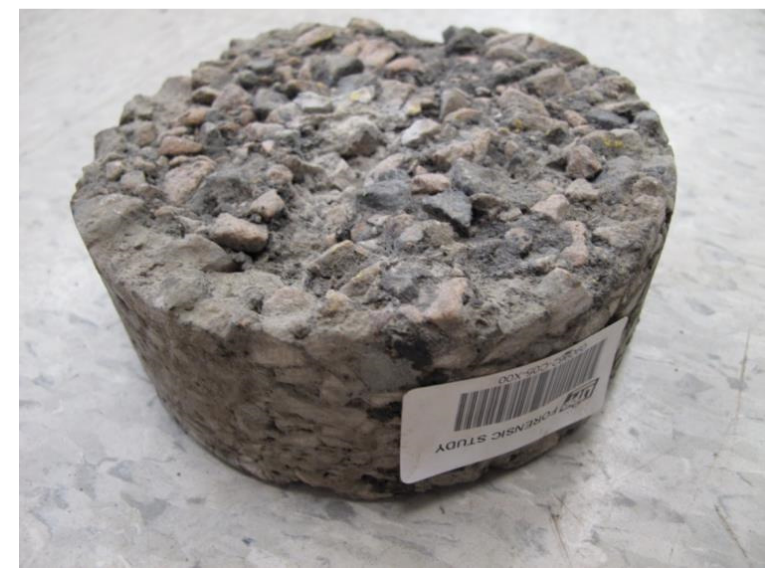

Fig. 2. LTPP field core from section 090962, stripping, i.e. moisture distress within test section

The final set of laboratory specimens were conditioned in the MiST. The procedure recommended by previous research submerges the specimens in water, maintained at $60{ }^{\circ} \mathrm{C}$ and applying $275.8 \mathrm{kPa}$ pore pressure at $0.5 \mathrm{~Hz}$ for $3,500 \mathrm{cycles}$. After the machine completes all 3,500 cycles, the cylinders are then submerged in a $25{ }^{\circ} \mathrm{C}$ water bath for 2 hours before performing the indirect strength test at $50 \mathrm{~mm} / \mathrm{min}$ displacement rate [10]. Fig. 3 presents the experimental test effort in a flow chart.

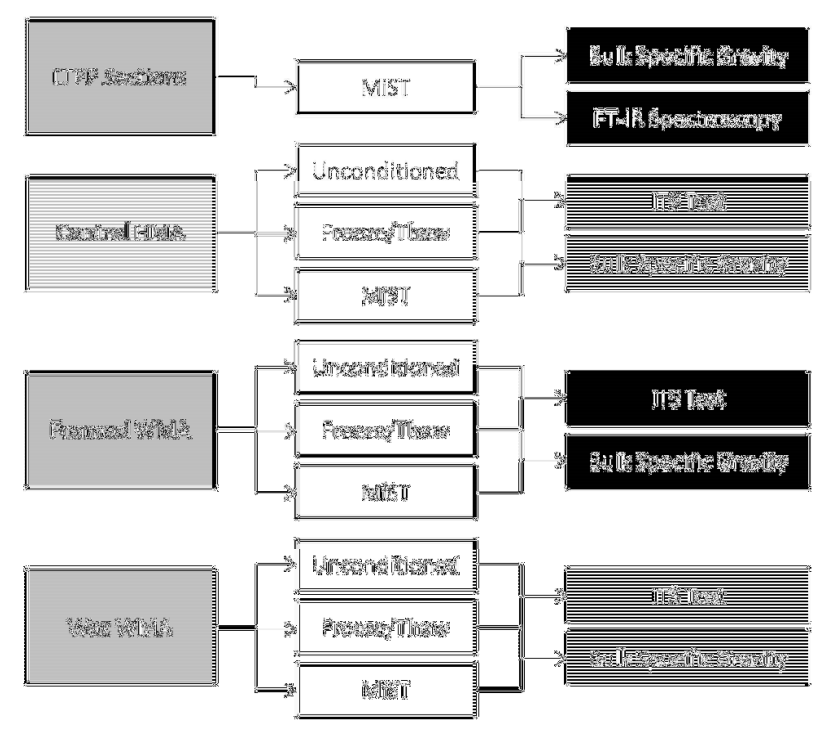

Fig. 3. Experimental flow chart

Laboratory WMA specimens were fabricated from the loose mix collected at the plant and reheated to the temperatures measured by thermal imaging of the mix arriving at the paver during construction. The target air voids for the samples was 7 $+/-0.5 \%$. Bulk specific gravity measurements were conducted using the automatic vacuum sealing method [11] for the field specimens and the Saturated Surface-Dry (SSD) method [12] was used for the laboratory compacted specimens both before and after conditioning.

It was hypothesized that adsorption-water displacement would occur during MiST conditioning. In order to test this hypothesis, water samples were collected before and after each LTPP test specimen was MiST treated and an Attenuated Total-Reflectance Fourier Transform Infrared-Spectrometer (ATR FT-IR) was used to analyze the samples. The water samples were measured in the ATR FT-IR in order to identify any absorbance peaks in the solution's spectra relating to 
asphalt. Previous studies used FT-IR in a controlled experiment to determine the diffusion rate of water through a thin film of asphalt [13].

\section{Discussion of results}

\subsection{LTPP sections}

Using the Core-Lok method [11] the bulk specific gravity of 3 specimens each were compared before and after MiST conditioning. The results from the comparison are illustrated in Fig. 4. It can be seen that Section 61 had the largest percent difference in its density after MiST conditioning. It is noteworthy that the results from the LTPP test sections containing RAP had a greater percent difference. However it is critical to note that these sections experienced other factors beyond the $20 \%$ RAP that could contribute to their larger deviation [14]. This report showed several instances of roller operational issues which may have affected the uniformity and density in these sections.

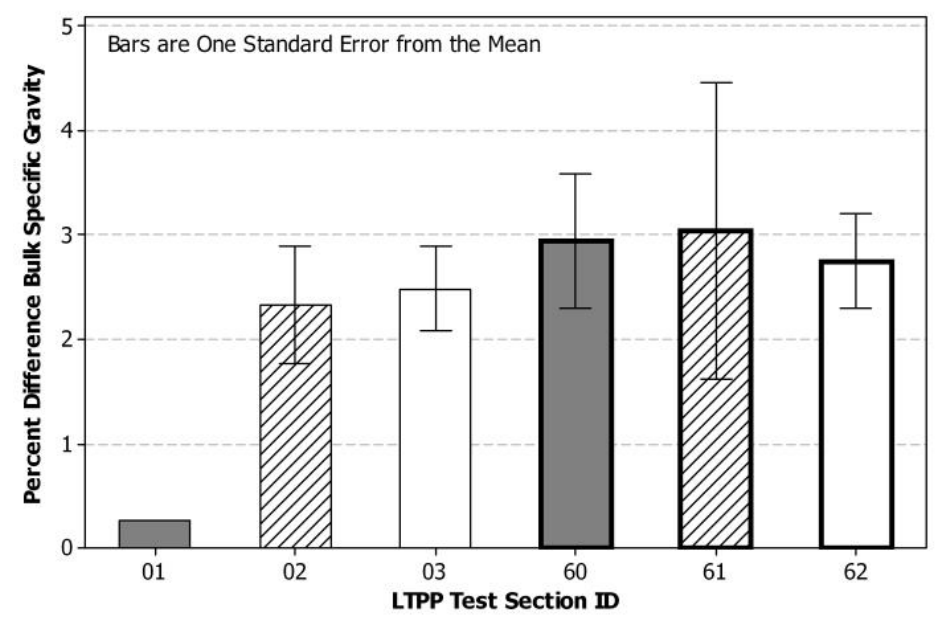

Fig. 4. Bulk Specific Gravity (BSG) percent difference pre-MiST/post-MiST. Thicker line weight borders indicate presence of RAP

Spectroscopic analysis of the water samples from each conditioning cycle were processed using the procedure developed and programmed in MATLAB environment [15]. Fig. 5 shows a sample of the post-processed spectra measured at the completion of the MiST tests compared to a baseline tap water sample. It can be seen that section LTPP-03 and LTPP-62 reflect several unique peaks as well as proportional peaks.

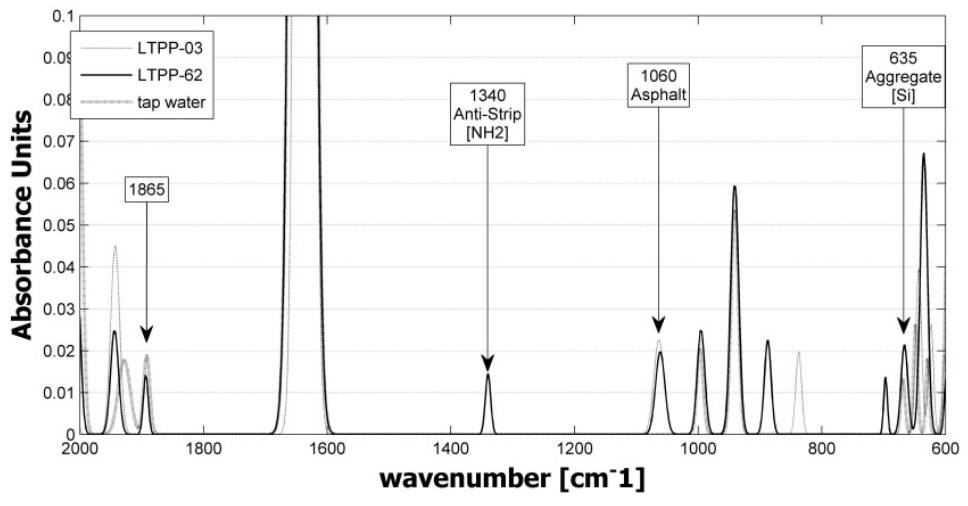

Fig. 5. Typical post-MiST spectra from two LTPP sections

In order to better understand the difference between the LTPP sections, a baseline correction and normalized band-area approach was used [15][16]. Comparative analysis was performed across all sections to identify the trends and unique peaks. Fig. $6 \mathrm{a}$ and $6 \mathrm{~b}$ show the relative band areas identified as relating to asphaltic materials [17] and how they changed for each section. 

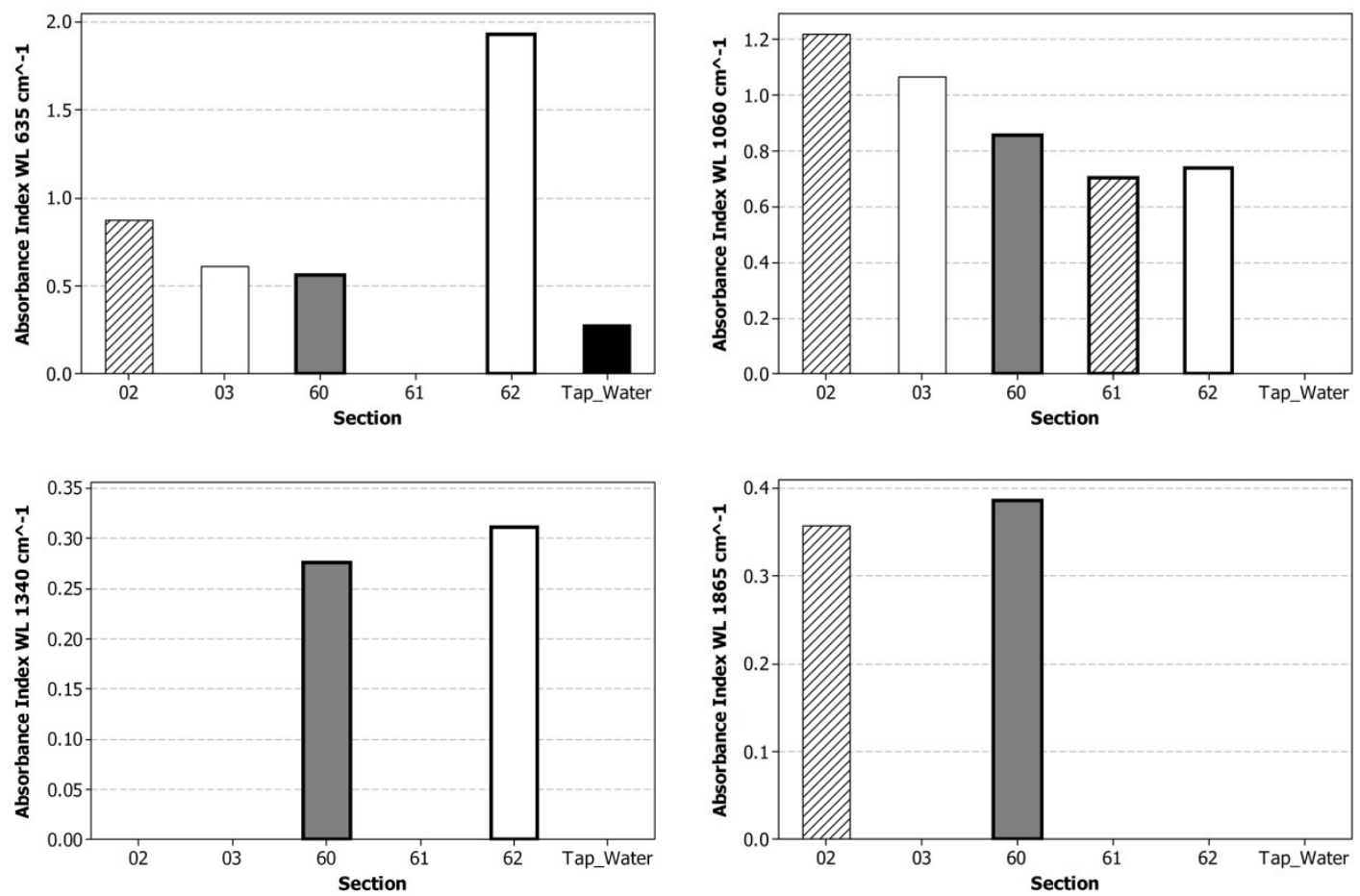

Fig. 6. Normalized band areas for post-MiST water samples at (a) wavelength $635 \mathrm{~cm}-1$ by section; (b) wavelength $1060 \mathrm{~cm}-1$ by section; (c) wavelength $1340 \mathrm{~cm}-1$ by section; (d) wavelength $1865 \mathrm{~cm}-1$ by section

Besides the peaks noted in Fig. 6, section 02 had measureable absorbance at $721 \mathrm{~cm}-1$ and section 61 had absorbance at $1456 \mathrm{~cm}-1$ which were both indicative of asphalt binder. The peaks shown in Fig. 6(c) are attributed to anti-stripping agent; this was predicted because the functional group associated with this peak (NH2) is typically found in anti-stripping agents and is less likely to be found in a pure binder. Additionally the peak in Fig. 6(a) was attributed to aggregate, the wavelength is commonly associated with Silica, which is a large portion of the chemical composition of all aggregate in Connecticut. Based on this visual analysis alone, it can be concluded that FT-IR spectroscopy can be used to identify the presence of asphalt binder in the post-MiST water.

Not only should asphalt be identifiable, however, but trends of leaching rates should be quantifiable from different mixes. To best identify the performance rates, the most prevalent spectroscopic peak was compared to the physical changes illustrated in Fig. 4. The results shown in Fig. 7 illustrate the correlation between structural deficiency and relative FT-IR index of wavelength $1060 \mathrm{~cm}-1$.

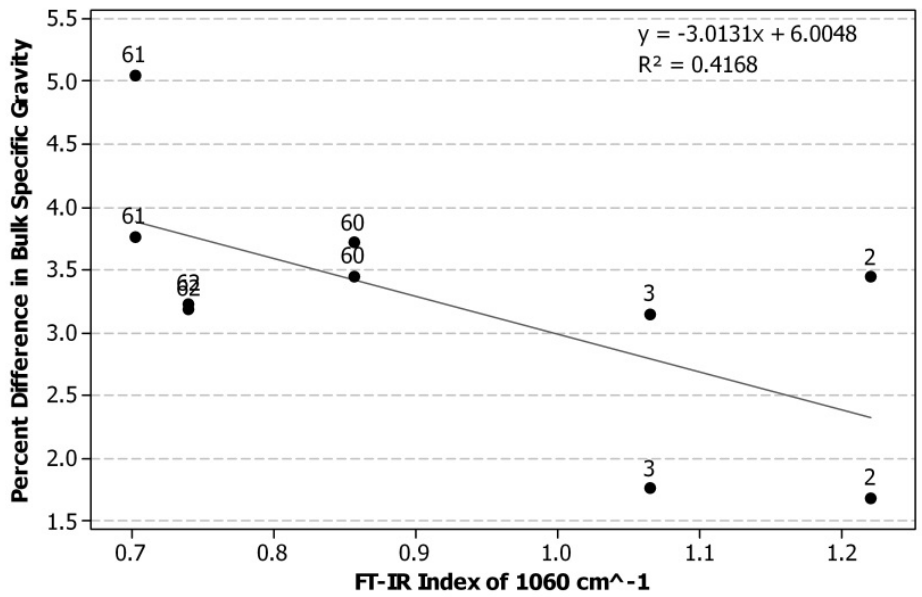

Fig. 7. Normalized Percent difference in bulk specific gravity versus relative spectra concentration at $1060 \mathrm{~cm}-1$ (numbers by markers indicate different LTPP sections)

The linear regression shown in Fig. 7 has a significant slope, but an R-squared value of only 0.42 . While this is identified as poor correlation, it is believed that the trend would grow to a stronger correlation with a larger data set. With this relationship identified, further work must be conducted to determine the underlying chemical reactions but it suggests that physical changes to the specimen inversely correlated to a higher relative absorbance of asphalt-related spectroscopic peaks 
in the water upon completion of MiST treatment. It is speculated that the weaker specimens (cores which had higher volumetric change) had already succumbed to stripping and thus previously leached a portion of their asphalt material leaving less behind available for detection in the MiST test.

\subsection{WMA sections}

The percent difference in bulk specific gravity for both field cores and laboratory produced WMA specimens is shown in Fig. 8. It can be seen that the field specimens showed a drastically smaller change relative to their laboratory counterparts after MiST conditioning. It is important to note that none of these mixtures was suspected to be prone to moisture. The laboratory compacted specimens for both WMA additives changed 1.0\% and the Sasobit WMA had the greatest change in density for any field specimens.

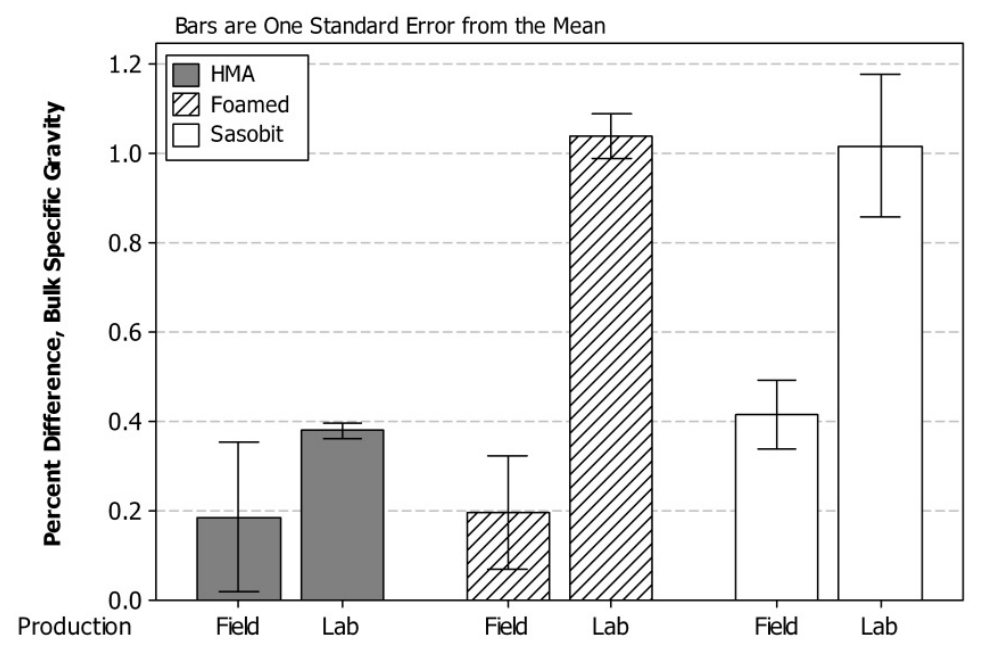

Fig. 8. Percent difference in Gmb for WMA field and laboratory specimens

In order to effectively determine the differences between standard AASHTO T283 and MiST conditioning, the individual strength test measurements were used to calculate the Tensile Strength Ratio (TSR) - a ratio of conditioned specimen strength to unconditioned specimen strength. By using individual instead of averaged values the variance is preserved from both strength tests when calculating average results. Triplicate strength measurements for each condition and treatment yielded 9 TSR measurements. The TSR values are shown in Fig. 9 while Fig. 10 contains the measured tensile strength.

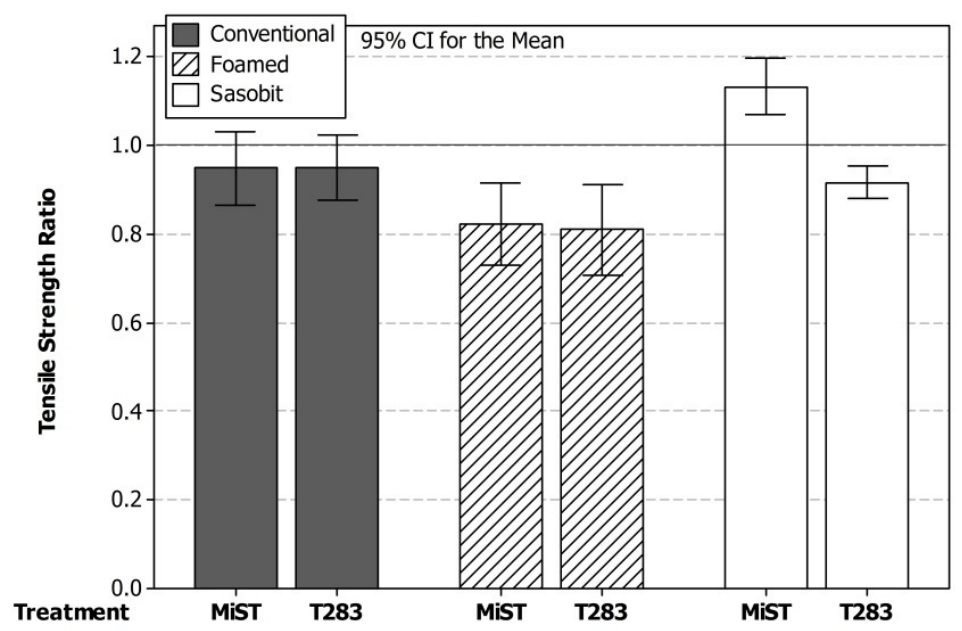

Fig. 9. TSR Results for from MiST and AASHTO T283 


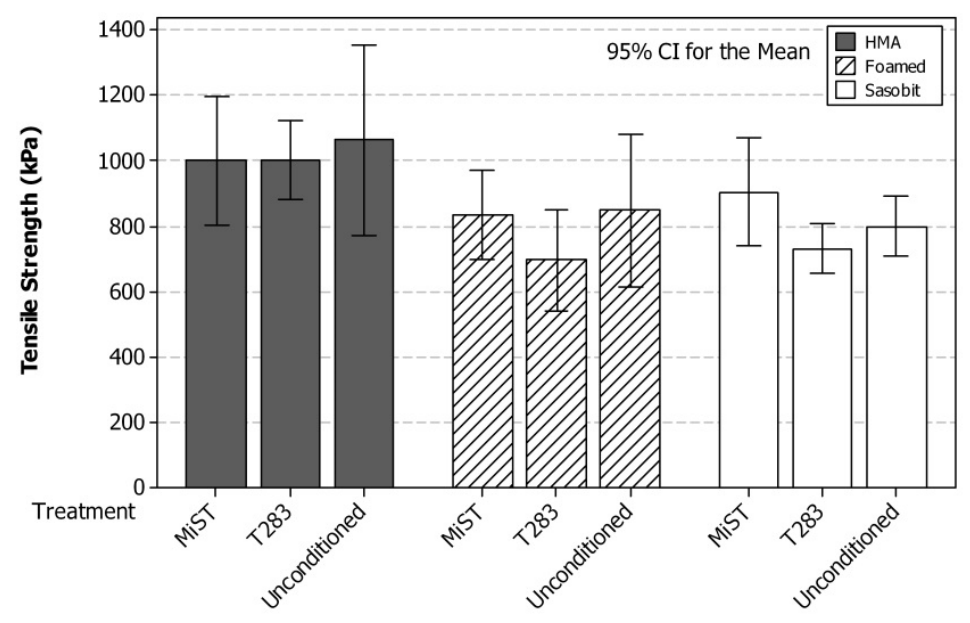

Fig. 10. Measured tensile strength by mixture and treatment

It can be seen in Fig. 9, the Sasobit test section did not match conventional AASHTO T283 conditioning and the MiST conditioning due to the lower strength values after T283 method. It suggests that a new criterion for the acceptance should be developed specifically for the MiST testing. The conventional HMA and foamed WMA section had statistically identical results for both accelerated conditioning procedures at a 95\% confidence level. The measured tensile strength results (Fig. 10) indicate higher average strengths for the HMA, and while the error bars show high variability an Analysis of Variance shows mix type being highly significant ( $p$-value $<0.001)$ and treatment is barely significant $(p$-value $=0.081)$. It is believed that with a larger data set, the significance of treatment type could be better determined. The results reported by [8] showed an increase in the TSR values for the foamed WMA that was MiST conditioned; the results from this study showed similar behavior for Sasobit mixes, but virtually no difference in the TSR values for the foamed mix.

\section{Conclusions}

This study evaluated the Moisture Induced Stress Test as a rapid moisture susceptibility conditioning apparatus. Using two warm-mix technologies, a control HMA and six LTPP test sections the MiST was validated and compared to the AASHTO T283 laboratory procedure used in Connecticut. Additionally, spectroscopic analysis using Attenuated Total Reflectance Fourier Transform Infrared Spectroscopy was implemented to identify the potential presence of asphalt in the water from MiST Testing. The following findings were noted:

- The Gmb for LTPP mixes containing RAP was greater than for non-RAP sections

- FT-IR Spectroscopic Analysis identified significant peaks relating to the presence of asphalt in the post-conditioned water for LTPP field cores at the $1060 \mathrm{~cm}-1$ wavelength

- Negative correlation was identified between percent-difference in Gmb and the $1060 \mathrm{~cm}-1$ absorbance-area index. This leads to speculation on the availability of asphalt material previously leached from the cores caused by moisture distresses.

- The presence of aggregate $(635 \mathrm{~cm}-1)$ and anti-stripping agent $(1865 \mathrm{~cm}-1)$ were identified in several post-MiST water samples from various LTPP sections

- The change in Gmb from the WMA field cores was much lower than the laboratory compacted specimens

- Tensile Strength Ratio correlated well for the HMA and WMA foamed but varied significantly for Sasobit wax

It can be concluded that the Moisture Induced Stress Test is a viable alternative test method for identifying moisture susceptibility. The use of spectroscopy as a means of quantifying moisture susceptibility should be further investigated but this study demonstrated the benefits of chemical analysis for explanation of physical behavior in the on-going effort to mitigate moisture susceptibility.

It is suggested that further sensitivity analysis should be conducted on the MiST device for its implementation in Connecticut using a wider variety of aggregates, gradations and binders. Furthermore a longer residence time in the MiST may provide for stronger differences in FT-IR spectra when collecting water samples from the MiST.

\section{Acknowledgements}

The authors would like to thank Ali Regimand and Instrotek for the use of the MiST machine and associated training with the machine. Additional gratitude is expressed to Dr. Iliya Yut for his assistance with spectroscopic analysis. Finally, the authors would like to thank John Dadalt, James Mahoney and the Connecticut Advanced Pavement Laboratory for 
conducting the AASHTO T283 portion of this study. The findings presented in this paper are solely authors' observations and are not necessary shared by any government agency and/or private organization.

\section{References}

[1] Tarrer, A.; Wagh, V. 1991. The Effect of the Physical and Chemical Characteristics of the Aggregate on Bonding. Strategic Highway Research Program, Report No. SHRP-A/UWP-91-510.

[2] Plancher, H; Dorrence, S. M.; Petersen, J. 1977. Identification of Chemical types in Asphalts Strongly Adsorbed at the Asphalt-Aggregate Interface and their Relative Displacement by Water, The Journal of the Association of Asphalt Pavement Technologists 46: 151-176.

[3] Petersen, J. C.; Plancher, H. 1998. Model Studies and Interpretive Review of the Competitive Adsorption and Water Displacement of Petroleum Asphalt Chemical Functionalities on Mineral Aggregate Surfaces, Petroleum Science and Technology 16:1-2, 89-131. http://dx.doi.org/10.1080/10916469808949774

[4] Song, Y; Wang, C.; Zhang, Z. 2011. Determination of the Chemical Composition in Asphalt Aqueous Solutions by SPE and GC/MS, Petroleum Science and Technology 29(15): 1590-1595. http://dx.doi.org/10.1080/10916461003620438

[5] Buchanan, M.; Moore, V. 2005. Laboratory Accelerated Stripping Simulator for Hot Mix Aggregate. Mississippi Department of Transportation, Report No. FHWA/MS-DOT-RD-04-167.

[6] Mallick, R.; Pelland, R.; Hugo, F. 2005. Use of accelerated loading equipment for determination of long term moisture susceptibility of hot mix asphalt. International Journal of Pavement Engineering 6(2): 125-136. http://dx.doi.org/10.1080/10916461003620438

[7] Chen, X.; Huang, B. 2008. Evaluation of Moisture Damage in Hot Mix Asphalt using Simple Performance and Superpave Indirect Tensile Tests, Construction and Building Materials 22: 1950-1962. http://dx.doi.org/10.1016/j.conbuildmat.2007.07.014

[8] Shu, X.; Huan, B.; Shrum, E.; Xiaoyang, X. 2012. Laboratory Evaluation of Moisture Susceptibility of Foamed Warm Mix Asphalt Containing High percentages of RAP. Construction and Building Materials 35: 125-130. http://dx.doi.org/10.1016/j.conbuildmat.2012.02.095

[9] Airey, G; Collop, A; Zoorob, S.; Elliot, R. 2008. The influence of Aggregate, Filler and Bitumen on Asphalt Mixture Moisture Damage, Construction and Building Materials. 22: 2015-2024. http://dx.doi.org/10.1016/j.conbuildmat.2007.07.009

[10] Resistance of Compacted Hot Mix Asphalt to Moisture-Induced Damage. 2011. American Association of State and Highway Transportation Officials, T283.

[11] Standard Test Method for Bulk Specific Gravity and Density of Compacted Bituminous Mixtures Using Automatic Vacuum Sealing Method. 2009. American Society for Testing Materials. D6752 - 09.

[12] Bulk Specific Gravity of Compacted Hot Mix Asphalt Using Saturated Surface-Dry Specimens. 2011. American Association of State and Highway Transportation Officials, T166.

[13] Vasconcelos, K.; Bhasin, A.; Little, D. 2010. Measurement of Water Diffusion in Asphalt Binders Using Fourier Transform Infrared-Attenuated Total Reflectance, Transportation Research Record: The Journal of the Transportation Research Board 2179: 29-38. http://dx.doi.org/10.3141/2179-04

[14]Larsen, D.; Rodrigues, N. 1997. Demonstration and Evaluation of Superpave Technologies, Construction Report from Route 2. The Connecticut Department of Transportation, FHWA-CT-RD2219-97-5.

[15] Yut, I.; Zofka, A. 2011. Attenuated Total Reflection Fourier Transform Infrared Spectroscopy of Oxidized Polymer-Modified Bitumens, Applied Spectroscopy 65(7): 765-770. http://dx.doi.org/10.1366/10-06217

[16]La Montagne, J.; Dumas, P.; Mouille, V.; Kisbér, J. 2001. Comparison by Fourier Transform Infrared (FT-IR) Spectroscopy of Different Aging Techniques: Application to Road Bitumens. Fuel 80:483-488. http://dx.doi.org/10.1016/S0016-2361(00)00121-6

[17]Petersen, J. C. 1986. Quantitative Functional Group Analysis of Asphalts Using Differential Infrared Spectrometry and Selective Chemical Reactions, Transportation Research Record: Journal of the Transportation Research Board 1096. 